\title{
Organic NIR Photodetectors: Pushing Photodiodes Beyond 1000 nm
}

\author{
Seth C. Rasmussen, ${ }^{*}$ Spencer J. Gilman, Evan W. Culver, and Wyatt D. Wilcox \\ Department of Chemistry and Biochemistry, North Dakota State University, NDSU Dept. 2735, \\ P.O. Box 6050, Fargo, ND 58108-6050, USA
}

Email: seth.rasmussen@ndsu.edu (S. C. R.)

\begin{abstract}
Advances in the synthesis of low bandgap $\left(E_{\mathrm{g}}<1.5 \mathrm{eV}\right)$ conjugated polymers has produced organic materials capable of absorbing near-infrared (NIR) light $(800-2500 \mathrm{~nm})$, with these materials first applied to photodiode NIR detectors in 2007 as an alternative to more traditional inorganic devices. Although the development of organic NIR photodetectors has continued to advance, their ability to effectively detect wavelengths in the low-energy portion of the NIR spectrum is still limited. Efforts to date concerning the production of photodiode-based devices capable of detecting light beyond $1000 \mathrm{~nm}$ are reviewed.
\end{abstract}

Keywords conjugated polymers, low bandgap polymers, NIR photodetectors, photodiodes, organic electronics

\section{Introduction}

Organic materials have grown to represent a lasting aspect of modern society such that organic plastics have become more ubiquitous than other common materials (e.g., metals, glass, or ceramics). While commonly associated with structural applications (e.g., plastics, resins, etc.), organic materials have grown to also include species for a range of optical and electronic applications, with conjugated organic materials playing a dominate role. ${ }^{[1-7]}$ As such conjugated materials combine the properties of organic plastics with the electronic properties of classical inorganic semiconductors, they are typically viewed as quite modern materials. In reality, however, conjugated organic polymers date back to the early 19 th century, ${ }^{[8,9]}$ although interest in their electronic properties did not really manifest until the early 1960s. ${ }^{[8-10]}$ Reports of conductivities in the metallic regime then brought specific focus to these materials in the $1970 s,{ }^{[8,9,11]}$ resulting in the addition of doped conjugated polymers to the growing class of synthetic metals. ${ }^{[12,13]}$ Before long, a broad interdisciplinary field had developed, ultimately leading to various technological applications and the current field of organic electronics, common examples of which include organic photovoltaics (OPVs), organic field-effect transistors (OFETs), organic light-emitting diodes (OLEDs), electrochromic devices, and chemical sensors. ${ }^{[1-7]}$

One limitation of organic materials is the inability to effectively absorb light deep into the near-infrared (NIR) spectrum $(800-2500 \mathrm{~nm})$. This has changed, however, with the ongoing development of low bandgap $\left(E_{\mathrm{g}}<1.5 \mathrm{eV}\right)$ polymers, ${ }^{[14-16]}$ which allows the realistic possibility of organic devices able to act as optical sensors for the detection of NIR light. While several reviews on organic NIR photodetectors have already been reported, these have either included photodetectors as a subset of larger topics ${ }^{[17-19]}$ or tend to focus on devices capable of sensing the higher energy edge of the NIR spectrum $(800-1000 \mathrm{~nm}) .{ }^{[20-22]}$ Due to the inherent difficulties in producing materials capable of effectively absorbing light at energies below $1000 \mathrm{~nm}$, photodetectors able to operate in this low-energy portion of the NIR spectrum are much less common. As such, the current review will summarize the progress to date on photodiode-based devices capable of detecting light beyond
$1000 \mathrm{~nm}$, while highlighting the current difficulties and limitations associated with their development.

\section{NIR Photodetectors}

Sensing NIR light plays a critical role in various applications. As such, NIR photodetector applications include optical communication, remote control, chemical sensing, nighttime surveillance, spectroscopy instrumentation, and medical monitoring devices for photodynamic therapy. ${ }^{[16-21]}$ Perhaps the most widespread of these uses lies in telecommunications, which transmit large amounts of data in the form of light through fiberoptic cables at wavelengths of 1150,1350 , and $1550 \mathrm{~nm} \cdot{ }^{[16]}$

Commercial NIR sensors utilize inorganic materials (GaAs, InGaAs, etc.) due to their excellent charge-carrier mobility, small exciton binding energy, and high stability. ${ }^{[1,20,21]}$ However, such inorganic devices have inherent drawbacks including complex and costly manufacturing, mechanical inflexibility, high driving voltage, low operating temperatures, and limited tunability of the spectral response range, all of which restrict their application to large-area, flexible, or portable devices. ${ }^{[17,20,21]}$ In contrast, organic photodetectors offer the potential of low-cost manufacturing, facile processing methods, light weight forms, high flexibility, and large-area scalability, while also providing tunable bandgaps, high quantum efficiency, and high sensitivity, thus making them promising alternatives to current commercial devices. ${ }^{[18,20,22]}$

Current approaches to organic NIR photodetectors include photoconductor, ${ }^{[21,22]}$ photodiode, ${ }^{[17-23]}$ and phototransistor ${ }^{[21,23]}$ devices (Figure 1), of which photodiodes were the first to be developed and are still the most commonly studied. In addition, photodetectors can be classified as broadband (panchromatic) or narrowband (wavelength selective), depending on the width of their spectral response window. ${ }^{[20]}$ The general device structure for most photodiode-based organic NIR photodetectors is essentially identical to conventional bulk heterojunction organic photovoltaic (BHJ OPV) devices. ${ }^{[19,20]}$ The performance of these devices, however, is typically characterized by somewhat different figure-of-merit parameters associated with the efficiency, noise, and speed of detection at a given wavelength $(\lambda) .{ }^{[19,20]}$ Like BHJ OPV devices, this includes the external quantum efficiency $(\operatorname{EQE}(\lambda))$, which is related to the device 


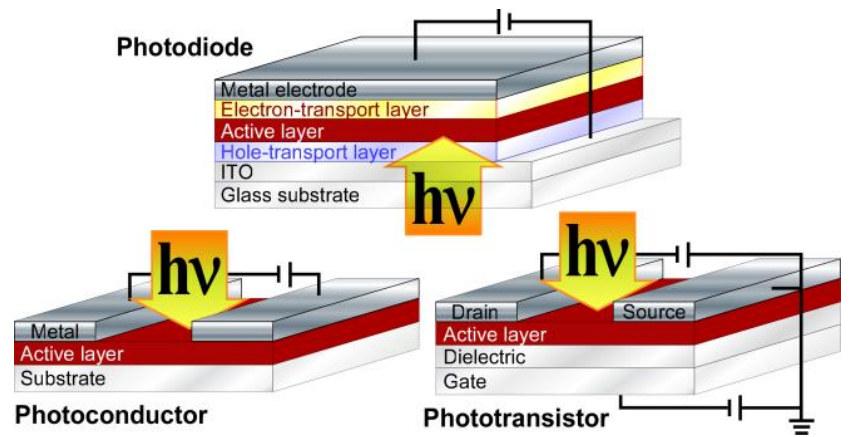

Figure 1 Primary types of organic NIR photodetector devices.

responsivity $(R(\lambda))$ at the wavelength in question. ${ }^{[18-20]}$ However, it is the specific detectivity $\left(D^{*}(\lambda)\right)$ that is considered the most critical parameter. ${ }^{[17-20]}$ This value is expressed in units of $\mathrm{cm}$ $\mathrm{Hz}^{1 / 2} \mathrm{~W}^{-1}$, which is equal to the more commonly cited unit of 1 Jones, with values $>10^{11}$ Jones considered satisfactory. Thus, $D^{*}(\lambda)$ is used to measure the ability to detect signals of weak irradiation intensity and can be improved by increasing $R(\lambda)$ and suppressing the dark current. ${ }^{[20]}$ Additional figures-of-merit include the noise equivalent power $(\operatorname{NEP}(\lambda))$, linear dynamic range $(\operatorname{LDR}(\lambda))$, temporal response time $(\tau),-3 \mathrm{~dB}$ bandwidth $\left(f_{-3 \mathrm{~dB}}\right)$, and spectral response range. ${ }^{[18-20]}$

\section{Low Bandgap Conjugated Polymers and the First Organic Materials with Photoresponse $>1000 \mathrm{~nm}$}

The ability to absorb sufficient NIR light requires an $E_{g}$ of $c a$. $1.5 \mathrm{eV}$ or lower and thus the design and synthesis of low $E_{\mathrm{g}}$ polymers is integral to the development of organic NIR photodetectors. In terms of design, various structure-function principles have been shown to contribute to lowered $E_{\mathrm{g}}$ values. These include both the degree of bond length alternation and planarity along the polymer backbone, as well as monomer aromaticity, the heteroatom of any heterocyclic units, and interchain coupling in the solid state. ${ }^{[14-16]}$ Although all of these factors play a role in the resulting $E_{g}$, two general design approaches are largely responsible for the successful generation of low $E_{g}$ polymers. The earliest of these was the application of fused-ring thiophenes that enhances the quinoidal nature of the polymer backbone, thus resulting in lower bandgaps. However, it is the application of "donor-acceptor" (D-A) frameworks that has become the prevalent design criteria for most low $E_{g}$ materials. ${ }^{[16]}$

Although these design principles have resulted in a wide variety of low bandgap polymers dating back to $1984,{ }^{[14-16]}$ the $E_{g}$ value alone does not ensure successful application to electronic devices. Thus, by 2010 , only 7 examples (Figure 2) provided the necessary combination of $E_{g}$, suitable frontier energy levels, and blend morphology to allow photoresponse at wavelengths greater than $1000 \mathrm{~nm}$ in BHJ OPV devices. ${ }^{[24-30]}$ With the exception of $\mathbf{3}$, all of these are copolymeric materials that utilize a combination of fused-ring quinoidal units and D-A frameworks to give $E_{g}$ values of $0.8-1.13 \mathrm{eV}$. Of the polymers given in Figure 2, polymer $\mathbf{5}$ provided the lowest energy onset at ca. $1450 \mathrm{~nm} .{ }^{[28]}$ Not surprisingly, it was from this initial set of materials that early organic NIR photodetectors were developed.

\section{Photodiode-Based Organic NIR Photodetectors}

\section{Polymer-based devices}

The first material to successfully exhibit photoresponse beyond $1000 \mathrm{~nm}$ was 1 (Figure 2) reported by Andersson and coworkers in 2007, with a spectral edge at $1200 \mathrm{~nm} .{ }^{[24]}$ Perhaps of little surprise, the authors recognized the potential application to NIR photodetectors and determined a peak NIR

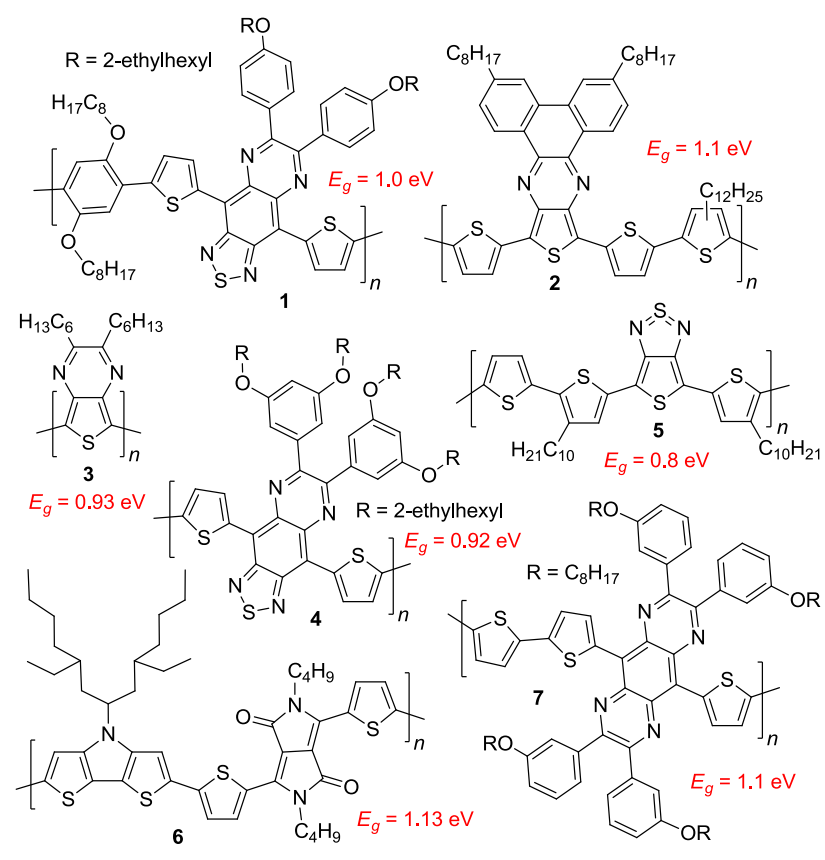

Figure 2 Initial materials capable of photoresponse $>1000$ nm.

Table 1 Select parameters of polymer NIR photodetectors

\begin{tabular}{|c|c|c|c|c|c|}
\hline layer $^{a}$ & $\mathrm{n}$ & $\begin{array}{l}\lambda_{\text {det }}(\mathrm{nm}) / \\
V_{\text {appl }}(\mathrm{V})\end{array}$ & $(\%)$ & $\begin{array}{c}D^{*}(\lambda) \\
\left(^{\text {Jones })^{b}}\right.\end{array}$ & Ref \\
\hline 1:PCBM & 20 & & 12.5 & & \\
\hline 5: & مח & 8 & & & [28] \\
\hline & 0 & & 28.9 & & \\
\hline 9:PCBM & 00 & 800 & 12.5 & $2.0 \times 10$ & [33] \\
\hline $5: \mathrm{PCBM}^{d, e}$ & ח & $800 /$ & 27.0 & 0 & 31 \\
\hline & 000 & & 2.6 & & \\
\hline 1 & $40 \mathrm{r}-2$ & & 16.0 & & [36] \\
\hline 11:P & 400 & $80 c$ & & & [3/] \\
\hline $10: P$ & 350 & 800 & 18.2 & 13 & [38] \\
\hline 12:P & 300 & 800 & & $4.1 \times 10^{11}$ & [39] \\
\hline M & 300 & 800 & & $1.0 \times 10^{11}$ & {$[3$} \\
\hline BM & 400 & & 5.8 & $1.04 \times 10^{12}$ & [40] \\
\hline 15:PCBM & 300 & 900 & & & [41] \\
\hline & 0 & & 01 & & [42] \\
\hline${ }_{1} \mathrm{BM}$ & 0 & $200 /$ & 7.8 & & [43] \\
\hline CBM & $350-2500$ & $1500 /-$ & 13.4 & $2.2 \times 10^{11}$ & [44] \\
\hline BM & 0 & 00 & 30 & $10^{12}$ & [45] \\
\hline
\end{tabular}

${ }^{a}$ PCBM $=[6,6]$-phenyl- $C_{61}$-butyric acid methyl ester; $\mathrm{PC}_{71} \mathrm{BM}=[6,6]-$ phenyl- $\mathrm{C}_{71}$-butyric acid methyl ester; triPCBM = triphenyl- $\mathrm{C}_{61}$-butyric acid methyl ester. ${ }^{b}$ Determined from dark current, unless otherwise noted. ${ }^{c}$ From noise current. ${ }^{d}$ Inverted device. ${ }^{e}$ With a ZnO nanowire array.

sensitivity at $950 \mathrm{~nm}$. From the reported $\operatorname{NEP}(\lambda)\left(2 \times 10^{-9} \mathrm{~W}\right)$ and the device area $\left(5 \mathrm{~mm}^{2}\right)$, this gives a $D^{*}(\lambda)$ of $5 \times 10^{9}$ Jones (Table 1). A month later, another NIR photodetector was also reported by $\mathrm{Yu}$, Yang, and coworkers, but this utilized a polymer with a higher $E_{g}$ and thus its spectral region did not extend beyond $970 \mathrm{~nm} .^{[31]}$

This was then followed up two years later by the more high-profile report of Heeger and coworkers on devices of 5 in 2009. ${ }^{[28]}$ Due to the lower $E_{g}$ of $\mathbf{5}$ in comparison to $\mathbf{1}$, this later 
work was able to extend the spectral region out to ca. $1450 \mathrm{~nm}$, although the peak sensitivity was blue-shifted to ca. $850 \mathrm{~nm}$. Still, the calculated $D^{*}(\lambda)$ at $800 \mathrm{~nm}$ was $2.3 \times 10^{13}$ Jones, significantly improved in comparison to the previous devices of 1 .

It was then another two years before a third example to extend beyond $1000 \mathrm{~nm}$ was reported by Meng, Chen, and co-workers in 2011. ${ }^{[32]}$ This was also the first report that utilized a new polymer that was not one of the original seven materials given in Figure 2. As shown in Figure 3, $\mathbf{8}$ was of similar design to the previous materials, exhibiting an $E_{\mathrm{g}}$ of $1.15 \mathrm{eV}$ and yielding devices with a spectral range out to $1100 \mathrm{~nm}$.
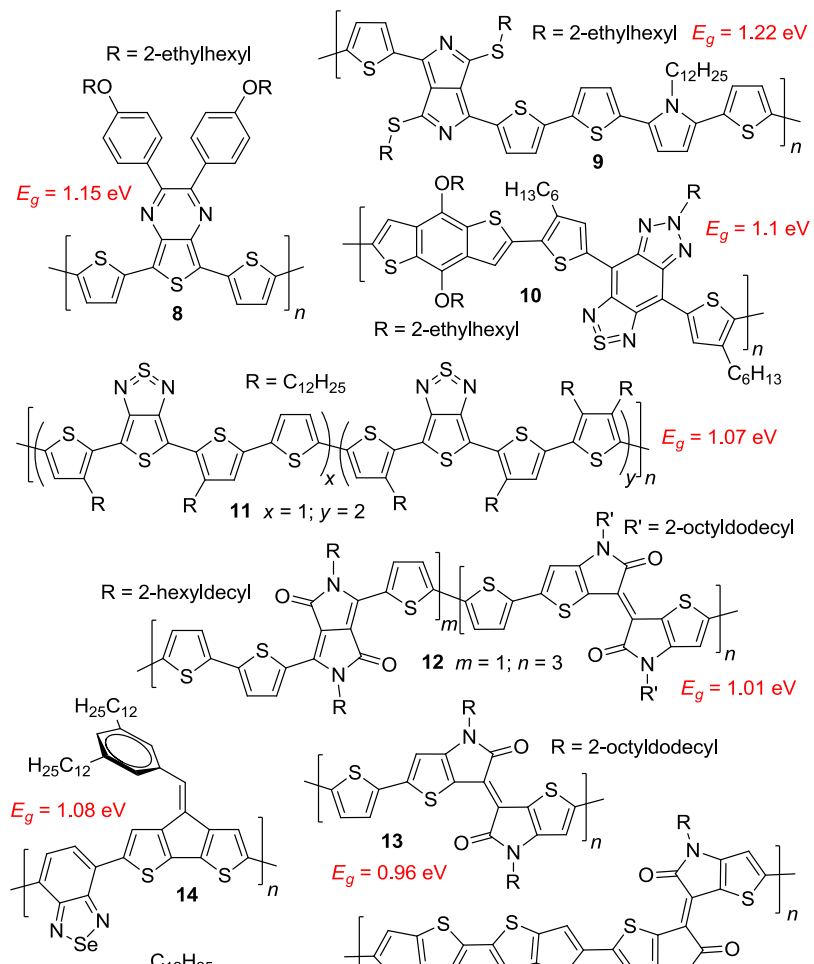

$\mathrm{R}$ R' $\quad E_{g}=1.01 \mathrm{eV}$

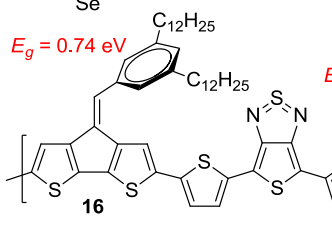<smiles>[R]O[R]#[R][H]</smiles>
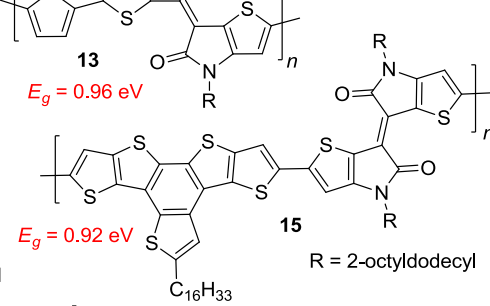<smiles>[R]OC1(C)C=CC=C(I)S1</smiles>
OR'
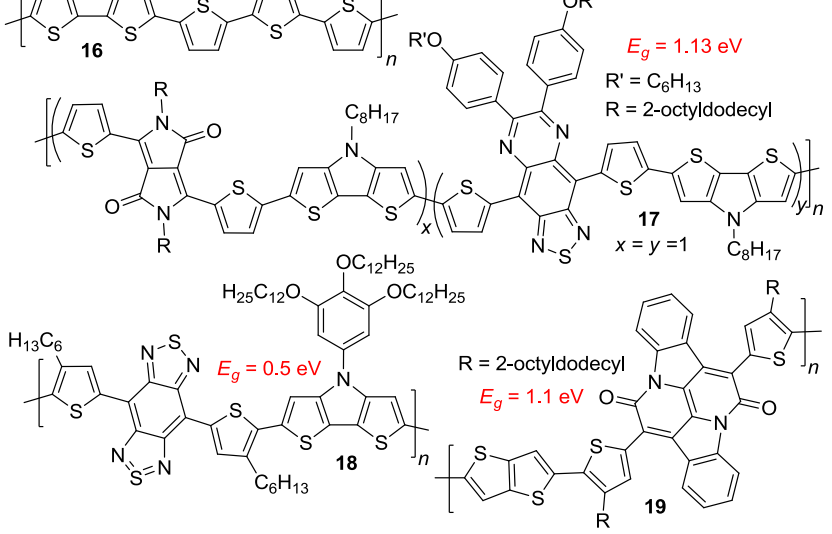

Figure 3 Additional NIR photodector materials after 2010.

From 2012 onward, reports of photodetectors capable of extending beyond $1000 \mathrm{~nm}$ become more common, with roughly two or more appearing each year. ${ }^{[33-46]}$ Of the devices given in Table 1, the next real advancement came in 2014, with devices of 10 (Figure 3) exhibiting a $D^{*}(\lambda)$ at $800 \mathrm{~nm}$ of $4.01 \times 10^{13}$ Jones, ${ }^{[38]}$ roughly twice that reported by Heeger and coworkers in 2009 . $^{[28]}$ Of course, this improvement was offset by a much narrower spectral region, only extending as far as $1100 \mathrm{~nm}$.
Further extension beyond the limit of $1450 \mathrm{~nm}$ set by Heeger and coworkers had to wait until 2017, when Qiao, Wang, and coworkers reported a photodetector with a spectral region out to $1600 \mathrm{~nm} .{ }^{[41]}$ This device utilized 15, with an $E_{\mathrm{g}}$ of $0.92 \mathrm{eV}$, thus significantly extending its ability to absorb lower energy NIR wavelengths. Although the maximum $D^{*}(\lambda)$ near $900 \mathrm{~nm}$ was a factor of 10 times lower than the previous devices of $5^{[28]}$ and $10,{ }^{[38]}$ it still exhibited a detectivity $>10^{11}$ Jones at $1300 \mathrm{~nm}$ and $>10^{10}$ Jones at $1600 \mathrm{~nm}$, thus showing great promise as a detector at lower energy wavelengths not previously possible.

The spectral region was further broadened that same year by Azoulay and coworkers, who reported a photodetector based on 16. ${ }^{[42]}$ As its bandgap $\left(E_{g}=0.74 \mathrm{eV}\right)$ was the lowest applied to NIR photodetectors to date, the resulting devices were now capable of response down to $1800 \mathrm{~nm}$. This extension of the spectral region was offset by significantly lower $D^{*}(\lambda)$ values, although still providing a detectivity of ca. $10^{8}$ Jones at $1800 \mathrm{~nm}$.

By far the greatest advancement, however, came in 2018 when Wudl and coworkers successfully extended the spectral region down to $2500 \mathrm{~nm} .{ }^{[44]}$ Again, this was achieved by further reducing the bandgap, with 18 exhibiting one of the lowest known bandgaps $\left(E_{g}=0.5 \mathrm{eV}\right)$ for a soluble, processible material. This allowed an especially broad photoresponse with a reasonable $D^{*}(\lambda)$ at $800 \mathrm{~nm}\left(1.4 \times 10^{11}\right.$ Jones $)$ and remaining above $10^{11}$ Jones out to ca. $2200 \mathrm{~nm}$.

Finally, an alternate approach was introduced in 2018 that moved the emphasis from the donor polymer of the BHJ to the acceptor material. ${ }^{[6]}$ Here, the fullerene component was replaced with small-molecule acceptors capable of NIR absorption. While early reports were limited to photoresponse below $1000 \mathrm{~nm}$, more recent efforts have led to spectral regions extending to $1100 \mathrm{~nm}$ with detectivities as high as $1.5 \times 10^{12}$ Jones. ${ }^{[47]}$

\section{Small molecule-based devices}

In addition to the polymer-based devices discussed above, alternate approaches have included various small molecule species capable of NIR absorption (Figure 4). ${ }^{[48-55]}$ While such species utilize the same design principles as low $E_{g}$ polymers, they are constrained by the shorter conjugation lengths of small molecules and thus typically rely on additional factors. The earliest such example was the application of porphyrin-tapes as reported by Forrest and coworkers in 2010. ${ }^{[48]}$ The most successful of these was 20 , which provided photoresponse over $400-1600 \mathrm{~nm}$ and a $D^{*}(\lambda)$ at $1350 \mathrm{~nm}$ of $2.3 \times 10^{10}$ Jones (Table 2). In a follow-up study, it was found that additives could improve device response. Thus, the addition of 4,4-bipyridine to a 20:PCBM device raised the $D^{*}(\lambda)$ at $1400 \mathrm{~nm}$ to $8.2 \times 10^{10}$

Table 2 Select parameters of small molecule photodetectors

\begin{tabular}{cccccc}
\hline $\begin{array}{c}\text { Active } \\
\text { layer }^{a}\end{array}$ & $\begin{array}{c}\text { Spectral } \\
\text { region }(\mathrm{nm})\end{array}$ & $\begin{array}{c}\lambda_{\text {det }}(\mathrm{nm}) / \\
V_{\text {appl }}(\mathrm{V})\end{array}$ & $\begin{array}{c}\mathrm{EQE}(\lambda) \\
(\%)\end{array}$ & $\begin{array}{c}D^{*}(\lambda) \\
(\text { Jones })\end{array}$ & Ref. \\
\hline 20:C 60 & $400-1600$ & $1350 / 0$ & 6.5 & $2.3 \times 10^{10}$ & {$[48]$} \\
20:PCBM:bpy & $400-1600$ & $1400 / 0$ & 10.5 & $8.2 \times 10^{10}$ & {$[49]$} \\
21:C 60 & $300-1100$ & $900 / 0$ & 18.0 & $2.34 \times 10^{11}$ & {$[50]$} \\
21:C ${ }_{70}$ & $300-1100$ & $890 / 0$ & 32.5 & $4.2 \times 10^{12}$ & {$[51]$} \\
22:PCBM & $300-1200$ & $1200 / 0$ & & $>10^{11}$ & {$[52]$} \\
23:C 60 & $400-1400$ & $1140 / 0$ & 1.1 & $5.3 \times 10^{10}$ & {$[53]$} \\
24:C 60 & $400-1500$ & $1390 / 0$ & 0.8 & $1.7 \times 10^{10}$ & {$[53]$} \\
23:perovskite & $500-1600$ & $1500 / 0$ & & $2 \times 10^{7}$ & {$[54]$} \\
${\text { 21: } C_{60}{ }^{b}}$ & $300-1100$ & $970 / 0$ & 6.3 & $9.01 \times 10^{12}$ & {$[55]$} \\
\hline
\end{tabular}

${ }^{a} \mathrm{PCBM}=[6,6]$-phenyl- $\mathrm{C}_{61}$-butyric acid methyl ester; bpy $=4,4^{\prime}$-bipyridine. ${ }^{b}$ Inverted device. 


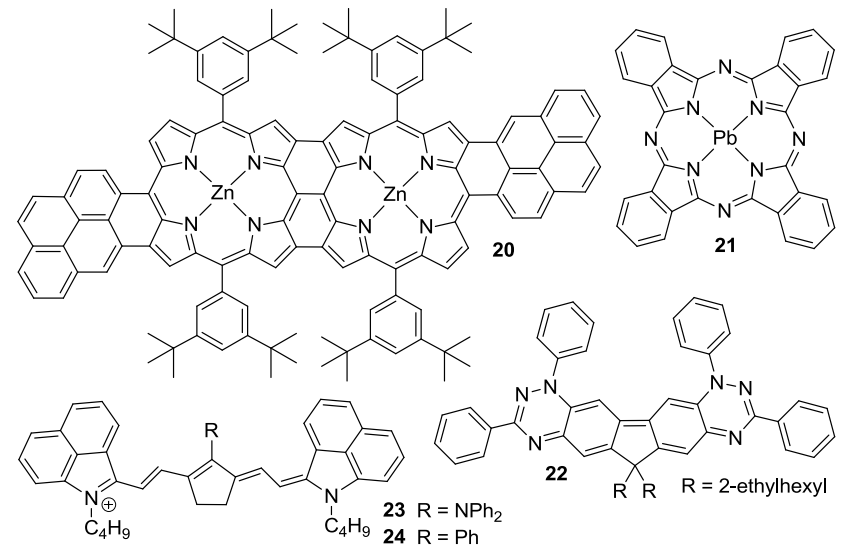

Figure 4 Small molecules giving photoresponse $>1000 \mathrm{~nm}$.

Jones. ${ }^{[49]}$

While none of the remaining small-molecule devices were able to extend the response beyond $1600 \mathrm{~nm}$, the phthalocyanine 21 did result in higher detectivity (ca. 10 $10^{12}$ Jones). ${ }^{[0,51,55]}$ The next best system for broad spectral response was the heptamethine $\mathrm{B}\left(\mathrm{C}_{6} \mathrm{~F}_{5}\right)_{4}$ salts 23 and 24. ${ }^{[33,54]}$ These provide similar detectivity to $\mathbf{2 0}$, with response to $1500 \mathrm{~nm}$. It was also found that 23:perovskite composites could extend this to 1600 $\mathrm{nm}$, although with a significant decrease in $D^{*}(\lambda) .^{[54]}$

\section{Conclusions and Perspectives}

As illustrated by the discussion above, strides have been made in extending the spectral region of organic NIR photodetectors, with devices of $\mathbf{1 8}$ exhibiting photoresponse across the full NIR spectrum $(800-2500 \mathrm{~nm}) .{ }^{[44]}$ While such achievements in organic NIR photodetectors are remarkable, it also needs to be pointed out that after 13 years of development, there are still only six polymers capable of photoresponse at energies lower than $1200 \mathrm{~nm} .^{[28,34,35,41-44]}$ If we add in the more successful small-molecule devices, ${ }^{[48,49,53,54]}$ that brings us up to nine materials for applications beyond $1200 \mathrm{~nm}$. Thus, while further advances can be made through efforts in film morphological control and interfacial reengineering ${ }^{[18]}$ thus improving EQE or $D^{*}(\lambda)$, the real need is the further development of new low $E_{g}$ materials capable of effective NIR absorption.

Of course, successfully producing conjugated materials that effectively combine low bandgaps, suitable solubility, and good film formation properties can still be a challenge. As seen in Figures 2 \& 3 , low $E_{g}$ materials generally incorporate various fused-ring units, which by their rigid nature tend to reduce polymer solubility. While this limitation can be overcome, it often requires bulky, branched sidechains that can inhibit interchain coupling, thus working against further $E_{g}$ reduction. Even if the desired combination of properties can be achieved, most really low bandgaps are achieved by destabilizing the material $\mathrm{HOMO}$, often to the point that the orbital energies are incompatible with typical device configurations. In this respect, newer approaches to low $E_{g}$ materials via stabilization of the polymer LUMO may be the key to future advances in NIR photodetectors. ${ }^{[56]}$

\section{Acknowledgements}

The authors wish to thank the National Science Foundation (CHE-2002877) and North Dakota State University for support of our work on low bandgap polymers and their applications.

\section{Author Contributions}

S. C. R. organized and wrote the initial manuscript, with the remaining authors collecting relevant literature and contributing to manuscript editing and revision.

\section{Conflict of Interest}

The authors declare no conflict of interest.

Copyright () 2021 Seth C. Rasmussen, Spencer J. Gilman, Evan W. Culver, and Wyatt D. Wilcox. This article is an open access article distributed under the terms and conditions of the Creative Commons Attribution (CC BY) license (http://creativecommons.org/licenses/by/ 4.0/). The use, distribution or reproduction in other forums is permitted, provided the original author(s) or licensor are credited and that the original publication in this journal is cited, in accordance with accepted academic practice. No use, distribution or reproduction is permitted which does not comply with these terms.

\section{References}

[1] Handbook of Conducting Polymers, 4th ed., Eds.: Reynolds, J. R.; Skotheim, T. A.; Thompson, B., CRC Press, Boca Raton, FL, 2019.

[2] Handbook of Thiophene-Based Materials, Eds.: Perepichka, I. F.; Perepichka, D. F., John Wiley \& Sons, Hoboken, 2009.

[3] Günes, S.: Neugebauer, H.; Sariciftci, N. S. Conjugated PolymerBased Organic Solar Cells. Chem. Rev. 2007, 107, 1324-1338.

[4] Scharber, M. C.; Sariciftci, N. S. Efficiency of bulk-heterojunction organic solar cells. Prog. Poly. Sci. 2013, 38, 1929-1940.

[5] Grimsdale, A. C.; Chan, K. L.; Martin, R. E.; Jokisz, P. G.; Holmes, A. B. Synthesis of Light-Emitting Conjugated Polymers for Applications in Electroluminescent Devices. Chem. Rev. 2009, 109, 897-1091.

[6] Rasmussen, S. C.; Evenson, S. J.; McCausland, C. B. Fluorescent Thiophene-based Materials and Their Outlook for Emissive Applications. Chem. Commun. 2015, 51, 4528-4543.

[7] Nielsen, C. B.; McCulloch, I. Recent advances in transistor performance of polythiophenes. Prog. Poly. Sci. 2013, 38, 2053-2069.

[8] Rasmussen, S. C. Early History of Conjugated Polymers: From their Origins to the Handbook of Conducting Polymers. In Handbook of Conducting Polymers, 4th ed, Eds.: Reynolds, J. R.; Skotheim, T. A.; Thompson, B., CRC Press, Boca Raton, FL, 2019, pp. 1-35.

[9] Rasmussen, S. C. Conjugated and Conducting Organic Polymers: The First 150 years. ChemPlusChem 2020, 85, 1412-1429.

[10] Rasmussen, S. C. Early History of Polypyrrole: The First Conducting Organic Polymer. Bull. Hist. Chem. 2015, 40, 45-55.

[11] Rasmussen, S. C. Acetylene and Its Polymers. 150+ Years of History. Springer Briefs in Molecular Science: History of Chemistry; Springer, Heidelberg, 2018.

[12] Rasmussen, S. C. On the origin of 'synthetic metals'. Mater. Today 2016, 19, 244-245.

[13] Rasmussen, S. C. On the Origin of "Synthetic Metals": Herbert McCoy, Alfred Ubbelohde, and the Development of Metals from Nonmetallic Elements. Bull. Hist. Chem. 2016, 41, 64-73.

[14] Rasmussen, S. C.; Pomerantz, M. Low Bandgap Conducting Polymers. In Conjugated Polymers: Theory, Synthesis, Properties, and Characterization, Eds.: Skotheim, T. A.; Reynolds, J. R., Handbook of Conducting Polymers, 3rd ed., CRC Press, Boca Raton, FL, 2007, Chapter 12.

[15] Roncali, J. Molecular Engineering of the Band Gap of $\pi$-Conjugated Systems: Facing Technological Applications. Macromol. Rapid Commun. 2007, 28, 1761-1775.

[16] Rasmussen, S. C. Low-Bandgap Polymers. In Encyclopedia of Polymeric Nanomaterials, Eds: Muellen, K.; Kobayashi, S., Springer, Heidelberg, 2015, pp. 1155-1166.

[17] Dou, L.; Yongsheng Liu, Y.; Hong, Y.; Li, G.; Yang, Y. Low-Bandgap Near-IR Conjugated Polymers/Molecules for Organic Electronics. Chem. Rev. 2015, 115, 12633-12665.

[18] Liu, C.; Wang, K.; Gong, X.; Heeger, A. J. Low bandgap semiconducting polymers for polymeric photovoltaics. Chem. Soc. Rev. 2016, 45, 4825-4846. 
[19] Xie, B.; Chen, Z.; Ying, L.; Huang, F.; Cao, Y. Near-infrared organic photoelectric materials for light-harvesting systems: Organic photovoltaics and organic photodiodes. InfoMat 2020, 2, 57-91.

[20] Liu, X.; Lin, Y.; Liao, Y.; Wu, J.; Zheng, Y. Recent advances in organic near-infrared photodiodes. J. Mater. Chem. C 2018, 6, 3499-3513.

[21] Li, Q.; Guo, Y.; Liu, Y. Exploration of Near-Infrared Organic Photodetectors. Chem. Mater. 2019, 31, 6359-6379.

[22] Chow, P. C. Y.; Someya, T. Organic Photodetectors for Next-Generation Wearable Electronics. Adv. Mater. 2020, 32, 1902045.

[23] Li, N.; Lan, Z.; Cai, L.; Zhu, F. Advances in solution-processable near-infrared phototransistors. J. Mater. Chem. C 2019, 7, 37113729.

[24] Perzon, E.; Zhang, F.; Andersson, M.; Mammo, W.; Inganäs, O.; Andersson, M. R. A Conjugated Polymer for Near Infrared Optoelectronic Applications. Adv. Mater. 2007, 19, 3308-3311.

[25] Petersen, M. H.; Hagemann, O.; Nielsen, K. T.; Jorgensen, M.; Krebs, F. C. Low band gap polythienopyrazines for solar cells -Introducing the 11-thia-9,13-diaza-cyclopenta[b]triphenylenes. Sol. Energy Mater. Sol. Cells 2007, 91, 996-1009.

[26] Wen, L.; Duck, B. C.; Dastoor, P. C.; Rasmussen, S. C. Poly(2,3dihexylthieno[3,4-b]pyrazine) via GRIM Polymerization: Simple Preparation of a Solution Processable, Low Band Gap Conjugated Polymer. Macromolecules 2008, 41, 4576-4578.

[27] Zoombelt, A. P.; Fonrodona, M.; Wienk, M. M.; Sieval, A. B.; Hummelen, J. C.; Janssen, R. A. J. Photovoltaic Performance of an Ultrasmall Band Gap Polymer. Org. Lett. 2009, 11, 903-906.

[28] Gong, X.; Tong, M.; Xia, Y.; Cai, W.; Moon, J. S.; Cao, Y.; Yu, G.; Shieh, C.-L.; Nilsson, B.; Heeger, A. J. High-Detectivity Polymer Photodetectors with Spectral Response from $300 \mathrm{~nm}$ to $1450 \mathrm{~nm}$. Science 2009, 325, 1665-1667.

[29] Zhou, E.; Wei, Q.; Yamakawa, S.; Zhang, Y.; Tajima, K.; Yang, C.; Hashimoto, K. Diketopyrrolopyrrole-Based Semiconducting Polymer for Photovoltaic Device with Photocurrent Response Wavelengths up to $1.1 \mu \mathrm{m}$. Macromolecules 2010, 43, 821-826.

[30] Wang, E.; Hou, L.; Wang, Z.; Hellstrõm, S.; Mammo, W.; Zhang, F.; Inganäs, O.; Andersson, M. R. Small Band Gap Polymers Synthesized via a Modified Nitration of 4,7-Dibromo-2,1,3-benzothiadiazole. Org. Lett. 2010, 12, 4470-4473.

[31] Yao, Y.; Liang, Y.; Shrotriya, V.; Xiao, S.; Yu, L.; Yang, Y. Plastic near-infrared photodetectors utilizing low band gap polymer. Adv Mater. 2007, 19, 3979-3983.

[32] Chen, E.-C.; Tseng, S.-R.; Chao, Y.-C.; Meng, H.-F.; Wang, C.-F.; Chen, W.-C.; Hsu, C.-S.; Horng, S.-F. Polymer infrared photodetector with high sensitivity up to $1100 \mathrm{~nm}$. Synth. Met. 2011, 161, 1618-1622.

[33] Qian, G.; Qi, J.; Wang, Z. Y. Synthesis and study of low-bandgap polymers containing the diazapentalene and diketopyrrolopyrrole chromophores for potential use in solar cells and near-infrared photodetectors. J. Mater. Chem. 2012, 22, 12867-12873.

[34] Yang, T.; Sun, K.; Liu, X.; Wei, W.; Yu, T.; Gong, X.; Wang, D.; Cao, Y. Zinc Oxide Nanowire As an Electron-Extraction Layer for Broadband Polymer Photodetectors with an Inverted Device Structure. J. Phys. Chem. C 2012, 116, 13650-13653.

[35] Duck, B. C.; Vaughan, B.; Wen, L.; Heth, C. L.; Rasmussen, S. C.; Zhou, X.; Belcher, W. J.; Dastoor, P. C. Probing the structure-function relationship in $\mathrm{PC}_{6} \mathrm{TP}: \mathrm{PCBM}$ based organic photonic devices. Sol. Energy Mater. Sol. Cells 2013, 110, 8-14.

[36] Hu, X.; Dong, Y.; Huang, F.; Gong, X.; Cao, Y. Solution-Processed High-Detectivity Near-Infrared Polymer Photodetectors Fabricated by a Novel Low-Bandgap Semiconducting Polymer. J. Phys. Chem. C 2013, 117, 6537-6543.

[37] Qi, J.; Zhou, X.; Yang, D.; Qiao, W.; Ma, D.; Wang, Z. Y. Optimization of Solubility, Film Morphology and Photodetector Performance by Molecular Side-Chain Engineering of Low-Bandgap Thienothiadiazole-Based Polymers. Adv. Funct. Mater. 2014, 24, 7605-7612.

[38] Hu, X.; Wang, K.; Liu, C.; Meng, T.; Dong, Y.; Liu, S.; Huang, F.; Gong, X.; Cao, Y. High-detectivity inverted near-infrared polymer photodetectors using cross-linkable conjugated polyfluorene as an electron extraction layer. J. Mater. Chem. C 2014, 2, 9592-9598.

[39] Qi, J.; Han, J.; Zhou, X.; Yang, D.; Zhang, J.; Qiao, W.; Ma, D.; Wang, Z. Y. Optimization of Broad-Response and High-Detectivity Polymer Photodetectors by Bandgap Engineering of Weak Donor-Strong Acceptor Polymers. Macromolecules 2015, 48, 3941-3948.

[40] Wu, Z.; Yao, W.; London, A. E.; Azoulay, J. D.; Ng, T. N. Temperature-Dependent Detectivity of Near-Infrared Organic Bulk Heterojunction Photodiodes. ACS Appl. Mater. Interfaces 2017, 9, 1654-1660.

[41] Han, J.; Qi, J.; Zheng, X.: Wang, Y.; Hu, L.; Guo, C.; Wang, Y.; Li, Y.; Ma, D.; Qiao, W.; Wang, Z. Y. Low-bandgap donor-acceptor polymers for photodetectors with photoresponsivity from $300 \mathrm{~nm}$ to 1600 nm. J. Mater. Chem. C 2017, 5, 159-165.

[42] London, A. E.; Huang, L.; Zhang, B. A.; Oviedo, M. B.; Tropp, J.; Yao, W.; Wu, Z.; Wong, B. M.; Ng, T. N.; Azoulay, J. D. Donor-acceptor polymers with tunable infrared photoresponse. Polym. Chem. 2017, 8, 2922-2930.

[43] Han, J.; Yang, D.; Ma, D.; Qiao, W.; Wang, Z. Y. Low-Bandgap Polymers for High-Performance Photodiodes with Maximal EQE near $1200 \mathrm{~nm}$ and Broad Spectral Response from 300 to $1700 \mathrm{~nm}$. Adv. Optical Mater. 2018, 6, 1800038.

[44] Zheng, L.; Zhu, T.; Xu, W.; Liu, L.; Zheng, J.; Gong, X.; Wudl, F. Solution-processed broadband polymer photodetectors with a spectral response of up to $2.5 \mu \mathrm{m}$ by a low bandgap donor-acceptor conjugated copolymer. J. Mater. Chem. C 2018, 6, 3634-3641.

[45] Verstraeten, F.; Gielen, S.; Verstappen, P.; Kesters, J.; Georgitzikis, E.; Raymakers, J.; Cheyns, D.; Malinowski, P.; Daenen, M.; Lutsen, L.; Vandewal, K.; Maes, W. Near-infrared organic photodetectors based on bay-annulated indigo showing broadband absorption and high detectivities up to $1.1 \mu \mathrm{m}$. J. Mater. Chem. C 2018, 6, 11645-11650.

[46] Gasparini, N.; Gregori, A.; Salvador, M.; Biele, M.; Wadsworth, A.; Tedde, S.; Baran, D.; McCulloch, I.; Brabec, C. J. Visible and Near-Infrared Imaging with Nonfullerene-Based Photodetectors. Adv. Mater. Technol. 2018, 3, 1800104

[47] Lee, J.; Ko, S.-J.; Lee, H.; Huang, J.; Zhu, Z.; Seifrid, M.; Vollbrecht, J.; Brus, V. V.; Karki, A.; Wang, H.; Cho, K.; Nguyen, T.-Q.; Bazan, G. C. Side-Chain Engineering of Nonfullerene Acceptors for Near-Infrared Organic Photodetectors and Photovoltaics. ACS Energy Lett. 2019, 4 1401-1409.

[48] Zimmerman, J. D.; Diev, V. V.; Hanson, K.; Lunt, R. R.; Yu, E. K.; Thompson, M. E.; Forrest, S. R. Porphyrin-Tape/ $\mathrm{C}_{60}$ Organic Photodetectors with 6.5\% External Quantum Efficiency in the Near Infrared. Adv. Mater. 2010, 22, 2780-2783.

[49] Zimmerman, J. D.; Yu, E. K.; Diev, V. V.; Hanson, K.; Thompson, M. E.; Forrest, S. R. Use of additives in porphyrin-tape/ $\mathrm{C}_{60}$ near-infrared photodetectors. Organic Electron. 2011, 12, 869-873.

[50] Wang, X.; Li, H.; Su, Z.; Fang, F.; Zhang, G.; Wang, J.; Chu, B.; Fang, X.; Wei, Z.; Li, B.; Li, W. Efficient organic near-infrared photodetectors based on lead phthalocyanine/ $\mathrm{C}_{60}$ heterojunction. Organic Electron. 2014, 15, 2367-2371.

[51] Su, Z.; Hou, F.; Wang, X.; Gao, Y.; Jin, F.; Zhang, G.; Li, Y.; Zhang, L.; Chu, B.; Li, W. High-Performance Organic Small-Molecule Panchromatic Photodetectors. ACS Appl. Mater. Interfaces 2015, 7, 2529-2534.

[52] Zheng, Y.; Miao, M.; Dantelle, G.; Eisenmenger, N. D.; Guang Wu, G; Yavuz, I.; Chabinyc, M. L.; Houk, K. N.; Wudl, F. A Solid-State Effect Responsible for an Organic Quintet. State at Room Temperature and Ambient Pressure. Adv. Mater. 2015, 27, 1718-1723.

[53] Young, M.; Suddard-Bangsund, J.; Patrick, T. J.; Pajares, N.; Traverse, C. J.; Barr, M. C.; Lunt, S. Y.; Lunt, R. R. Organic Heptamethine Salts for Photovoltaics and Detectors with Near-Infrared Photoresponse up to $1600 \mathrm{~nm}$. Adv. Optical Mater. 2016, 4, 1028-1033.

[54] Lin, Q.; Wang, Z.; Young, M.; Patel, J. B.; Milot, R. L.; Maestro, L. M.; Lunt, R. R.; Snaith, H. J.; Johnston, M. B.; Herz, L. M. Near-Infrared and Short-Wavelength Infrared Photodiodes Based on Dye-Perovskite Composites. Adv. Funct. Mater. 2017, 27, 1702485.

[55] Choi, M.-S.; Chae, S.; Kim, H. J.; Kim, J.-J. Control of Crystallinity in 
PbPc: $\mathrm{C}_{60}$ Blend Film and Application for Inverted Near-Infrared Organic Photodetector. ACS Appl. Mater. Interfaces 2018, 10, 25614-25620.

[56] Culver, E. W.; Anderson, T. E.; Navarrete, J. T. L.; Delgado, M. C. R.; Rasmussen, S. C. Poly(thieno[3,4-b]pyrazine-alt-2,1,3-benzothiadiazole)s: A New Design Paradigm in Low Band Gap Polymers.
ACS Macro Lett. 2018, 7, 1215-1219.

Received October 30, 2020

Accepted December 1, 2020 